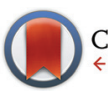

CrossMark

$\leftarrow$ click for updates

Cite this: Polym. Chem., 2015, 6 , 7280

Received 6th May 2015, Accepted 27th May 2015

DOI: $10.1039 / c 5 p y 00668 f$

www.rsc.org/polymers

\section{The effect of molecular weight on the porosity of hypercrosslinked polystyrene $\uparrow$}

\author{
Thanchanok Ratvijitvech, Michael Barrow, Andrew I. Cooper and Dave J. Adams*
}

\section{Introduction}

Microporous organic polymers (MOPs) are useful materials with pores smaller than $2 \mathrm{~nm} .{ }^{1}$ The porous structure and high stability of these materials have led to them being investigated widely for gas storage and sorption, ${ }^{2}$ separation, ${ }^{3}$ catalysis,${ }^{4}$ and energy storage. ${ }^{5,6}$ There are many kinds of MOPs, as classified by their structures, including covalent organic frameworks (COFs) ${ }^{7,8}$ covalent triazine frameworks (CTFs), ${ }^{9}$ polymers of intrinsic microporosity (PIMs), ${ }^{10}$ hypercrosslinked polymers (HCPs), ${ }^{11}$ conjugated microporous polymers (CMPs), ${ }^{12}$ porous aromatic frameworks (PAFs), ${ }^{13}$ and porous polymer networks (PPNs), ${ }^{14,15}$ among others. Tuning of the porosity and chemical properties of the networks is important for the design of these polymers for specific uses. ${ }^{16-18}$

The so-called "knitting method" is an effective and efficient method to construct porous networks. ${ }^{19}$ Here, a Friedel-Crafts reaction is used to cross-link rigid aromatic building blocks to form HCPs. A number of aromatic monomers have been used, including benzene,${ }^{19}$ toluene, ${ }^{19}$ carbazole,${ }^{20}$ indoles $^{21}$ and thiophenes. ${ }^{22}$ However, the limitation of the Friedel-Crafts reaction is that the reaction is generally unsuccessful if there is an electron-withdrawing group such as a carboxylic acid on the benzene ring. ${ }^{23,24}$ Such functional groups are of course useful in many applications; for example, to adjust the polarity of the networks for selective extractions. ${ }^{25-27}$ As one example, a carboxylic acid functionalised CMP was shown to have a strong interaction with carbon dioxide as compared to polymer networks containing other functional groups. ${ }^{28}$ It is also possible to transform carboxylic acids into esters, amides, etc.

Department of Chemistry, University of Liverpool, Crown Street, Liverpool, L69 7ZD, UK.E-mail: d.j.adams@liverpool.ac.uk

$\dagger$ Electronic supplementary information (ESI) available: Further IR data. See DOI: 10.1039/c5py00668f
Hence, the incorporation of carboxylic acids into HCP networks, while retaining porosity, would be interesting and useful.

Direct hypercrosslinking of polystyrene was pioneered by Davankov et $a l^{29}$ These networks were modified and used in many applications, including separation ${ }^{30-32}$ as well as gas storage ${ }^{33,34}$ and catalysis. ${ }^{35}$ It is also possible to hypercrosslink polystyrene films ( $\left.M_{\mathrm{w}} c a .15900 \mathrm{Da}\right)$ to form porous membranes. ${ }^{36}$ Many researchers have focused on varying synthetic conditions, such as the degree of crosslinking, and the resulting effect on the surface areas of the polymers. ${ }^{37-42}$ Previously, surface areas were found to be independent of the linear polystyrene molecular weight for polymers ranging from $8.8 \times 10^{3}$ to $3 \times 10^{6} \mathrm{Da}^{43}$ However, to the best of our knowledge, hypercrosslinking of low molecular weight linear polystyrene has not been examined. Recently, Zhang et al. have showed the influence of molecular weight of linear poly-p-phenylenes on the porosity properties of the networks after crosslinking. ${ }^{44}$ The surface areas and pore volumes were found to first rise and then fall again as the molecular weight was increased.

In this paper, we examine the "knitting" of a series of linear polystyrenes, synthesised by reversible addition-fragmentation chain transfer (RAFT) polymerisation. ${ }^{45}$ RAFT polymerisation is one of the most effective ways to synthesise polymers with well-defined functional structures and molecular weights. We decided to prepare the polystyrenes using RAFT as opposed to another living radical technique, since RAFT is tolerant of carboxylic acid groups. ${ }^{46}$ There are several commercially available RAFT agents available containing carboxylic acids. By using carboxylic acid containing RAFT agents, linear polystyrenes with pendant carboxylic acids were obtained. After crosslinking by the Friedel-Craft reaction (Scheme 1), we investigated the effect of the presence of the carboxylic acid and the degree of polymerisation of the polymer on the porosity properties of resulting networks. 


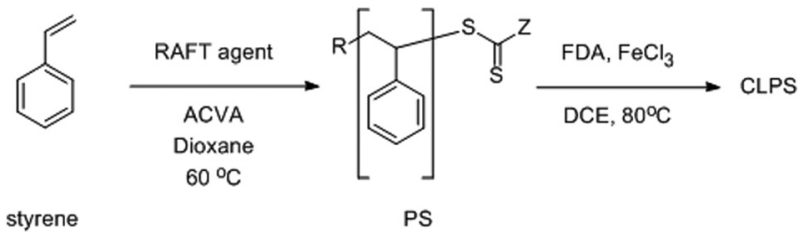

Scheme 1 Synthesis of hypercrosslinked polystyrene (CLPS).

\section{Experimental}

\section{Materials and methods}

All reagents were purchased from Sigma Aldrich. Styrene was passed through alumina to remove the inhibitor before use. All other chemicals were used as received.

Synthesis of linear polystyrenes. Linear polystyrenes were synthesised by RAFT polymerisation. In an example synthesis, to a solution of 4-cyano-4-[(dodecylsulfanylthiocarbonyl) sulfanyl]pentanoic acid (RAFT-1) (1 eq., $0.72 \mathrm{mmol}, 0.29 \mathrm{~g}$ ) in dioxane $(7.5 \mathrm{~mL}$ ) was added styrene (25 eq., $18 \mathrm{mmol}, 2.1 \mathrm{~mL}$ ) and 4,4'-azobis(4-cyanovaleric acid) (ACVA) (0.5 eq., $0.36 \mathrm{mmol}$, $0.10 \mathrm{~g})$. The solution was deoxygenated by nitrogen purging for 30 minutes. The reaction was then heated to $60^{\circ} \mathrm{C}$ and stirred under nitrogen. The conversion was monitored by ${ }^{1} \mathrm{H}$ NMR. After 90 hours, the reaction was cooled to room temperature and the product precipitated into ethanol (EtOH). After drying in vacuo at $40{ }^{\circ} \mathrm{C}$ overnight, $\mathbf{P S}_{1-7}$ was obtained as yellow solid in an $87 \%$ yield. ${ }^{1} \mathrm{H} \mathrm{NMR}\left(\mathrm{CDCl}_{3}, 400 \mathrm{MHz}\right) \delta=0.88(\mathrm{~m}, 3 \mathrm{H})$, 0.90-2.50 (m, 89H), 3.25 (m, 2H), 4.62-5.07 (m, 1H), 6.25-7.35 $(\mathrm{m}, 105 \mathrm{H})$ ppm. GPC: $M_{\mathrm{n}}=2609, M_{\mathrm{w}}=2783$, PDI $=1.07$. Elemental analysis: calculated (\%) for $\mathrm{C}_{187} \mathrm{H}_{201} \mathrm{NO}_{2} \mathrm{~S}_{3}$ : C 86.69, H 7.82, N 0.54, S 3.71; found: C 86.86, H 7.74, N 0.57, S 3.17. For other polymers, the molecular weight of the polystyrene was varied by adjusting the amount of RAFT agent and initiator used. Other RAFT agents were also used where described (see text).

Crosslinking of linear polystyrenes. The crosslinking of polystyrene was performed followed the method of Li et al. ${ }^{19}$ As an example synthesis, to a solution of the linear polystyrene $\left(\mathbf{P S}_{1-7}\right)$ (0.1 mmol, $\left.0.26 \mathrm{~g}\right)$ in 1,2-dichloroethane (DCE) (4.2 mL) was added formaldehyde dimethyl acetal (FDA) $(4.2 \mathrm{mmol}$, $0.4 \mathrm{~mL}$ ) and iron(III) chloride $\left(\mathrm{FeCl}_{3}\right)(4.2 \mathrm{mmol}, 0.68 \mathrm{~g})$. The reaction was heated to $80{ }^{\circ} \mathrm{C}$ overnight under nitrogen. The reaction was quenched by adding methanol $(\mathrm{MeOH})$. The solid product was collected by filtration and washed well with $\mathrm{MeOH}$. The product was further purified by Soxhlet extraction using $\mathrm{MeOH}$ for three days and dried in vacuo at $70{ }^{\circ} \mathrm{C}$ overnight. The resulting crosslinked polystyrene (CLPS $\left.{ }_{1-7}\right)$ was obtained as a brown solid in a $99 \%$ yield. Elemental analysis: calculated (\%) for $\mathrm{C}_{229} \mathrm{H}_{243} \mathrm{NO}_{2} \mathrm{~S}_{3}$ : C 87.66, $\mathrm{H} 7.81, \mathrm{~N} 0.45$, S 3.07; found: C 81.82, H 6.94, N 0.46, S 1.50. For other polymers, the amount of FDA, $\mathrm{FeCl}_{3}$ and solvent used was adjusted in the proportion to the number of styrene units in the linear polystyrene.

\section{Characterisation}

Fourier transform infrared (FTIR). IR spectra were measured on a Bruker Tensor 27 using pressed $\mathrm{KBr}$ discs for crosslinked networks and attenuated total reflection (ATR) for monomers and linear polystyrenes. The resolution of the measurement was $2 \mathrm{~cm}^{-1}$ with a background subtraction of a blank $\mathrm{KBr}$ disc or air as appropriate.

Gel permeation chromatography (GPC). GPC data were collected on a Viscotek system, which was comprised of a GPCmax solvent/sample module, and a TDA302 detector module housing a refractive index, viscometer and lightscattering detectors. The system was fitted with $2 \times$ ViscoGel HHR-H columns housed in an oven at $40{ }^{\circ} \mathrm{C}$, and $\mathrm{THF}$ was used as the eluent. The system was calibrated with low molecular weight polystyrene standards, and the OmniSEC Universal calibration method was used.

Gas sorption. Samples for gas sorption studies were degassed at $120^{\circ} \mathrm{C}$ under vacuum for 900 minutes prior to the measurements. Nitrogen sorption isotherms were collected using Micromeritics ASAP 2420 instrument at 77.3 K. Surface areas were calculated using Brunauer-Emmett-Teller (BET) theory over the relative pressure range of $0.05-0.15 P / P_{0}$. Carbon dioxide uptakes were obtained from Micromeritics ASAP 2020 physisorption analyser at $273 \mathrm{~K}$ and $298 \mathrm{~K}$.

\section{Results and discussion}

\section{Synthesis of linear polystyrenes}

A series of linear polystyrenes with different molecular weights containing carboxylic acid functional groups were synthesised by RAFT polymerisation. ${ }^{47}$ A number of different RAFT agents were investigated, including three that contained a carboxylic acid (Fig. 1).

When using RAFT-1, RAFT-3, and RAFT-4, the resulting polystyrenes were obtained as pale yellow to yellow solids in yields of between $65-80 \%$ yields. The colour of the polymers was found to be more yellow at lower molecular weights. The polymers are named $\mathbf{P S}_{\boldsymbol{x}-\boldsymbol{y}}$, with $x$ referring to the RAFT agent used, and $y$ referring to the sample number (Table 1). As expected, the rate of polymerisation was slower rate when using RAFT-2 and RAFT-5, as the radical fragmentation rate of these RAFT agents is known to be lower. ${ }^{4,49}$ For these two RAFT agents, after 90 hours, only around a 50\% conversion

$$
\text { RAFT-1 }
$$
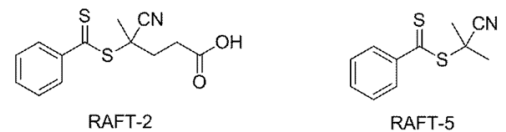

Fig. 1 Structures of the RAFT agents used in this study. 
Table 1 Summary of data for the linear polystyrenes

\begin{tabular}{lrrrrrr}
\hline Sample & $\% \mathrm{~N}$ & $\% \mathrm{~S}$ & $M_{\mathrm{W}}$ & $M_{\mathrm{n}}$ & PDI & DP \\
\hline PS $_{1-1}$ & 2.81 & 9.42 & 1060 & 950 & 1.12 & 5 \\
PS $_{1-2}$ & 1.18 & 7.23 & 1350 & 1220 & 1.11 & 8 \\
PS $_{1-3}$ & 1.16 & 5.82 & 1670 & 1490 & 1.12 & 10 \\
PS $_{1-4}$ & 0.84 & 5.30 & 1790 & 1680 & 1.07 & 12 \\
PS $_{1-5}$ & 0.84 & 4.81 & 2200 & 2060 & 1.07 & 16 \\
PS $_{1-6}$ & 0.79 & 3.58 & 2320 & 1960 & 1.18 & 15 \\
PS $_{1-7}$ & 0.57 & 3.17 & 2780 & 2610 & 1.07 & 21 \\
PS $_{1-8}$ & 0.37 & 1.82 & 4140 & 3740 & 1.11 & 32 \\
PS $_{1-9}$ & 0.30 & 1.51 & 5090 & 4520 & 1.13 & 39 \\
PS $_{1-10}$ & 0.27 & 1.21 & 5700 & 5040 & 1.13 & 45 \\
PS $_{2-1}$ & 1.50 & 4.76 & 1460 & 1180 & 1.24 & 11 \\
PS $_{2-2}$ & 0.55 & 1.77 & 3280 & 2940 & 1.11 & 24 \\
PS $_{3-1}$ & 0.61 & 7.07 & 1350 & 1140 & 1.18 & 10 \\
PS $_{3-2}$ & 0.20 & 3.21 & 2790 & 2500 & 1.11 & 23 \\
PS $_{4-1}$ & 1.60 & 9.46 & 1170 & 980 & 1.20 & 7 \\
PS $_{4-2}$ & 0.72 & 4.01 & 2350 & 2170 & 1.08 & 19 \\
PS $_{5-1}$ & 1.50 & 5.40 & 1200 & 1030 & 1.16 & 9 \\
PS $_{5-2}$ & 0.67 & 2.60 & 2440 & 2210 & 1.10 & 19 \\
& & & & & &
\end{tabular}

was obtained. Therefore, a higher amount of styrene monomer was used in polymerisation reactions to provide the linear polystyrenes with the target styrene units. $\mathbf{P S}_{2-y}$ and $\mathbf{P S}_{5-y}$ were pink followed the colour of the RAFT agents used with $50-60 \%$ conversion.

${ }^{1} \mathrm{H}$ NMR spectra showed all the expected resonances, including those for the RAFT agent. The ratio of the integrals from the aromatic protons to those of the RAFT agent increased with increasing molecular weight. After purification by precipitation, no residual monomer was detected, as shown by the absence of the vinyl proton peaks at 5.27 and $5.83 \mathrm{ppm}$ (Fig. 2). Elemental analysis illustrated the decrease of sulphur (S) and nitrogen $(\mathrm{N})$ content as the number of styrene units increased.

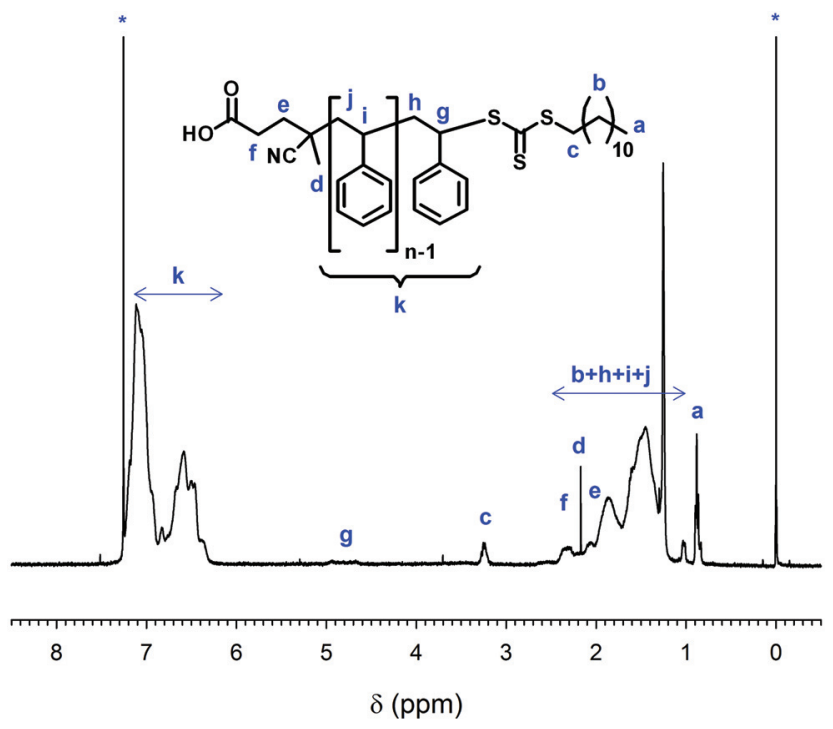

Fig. $2{ }^{1} \mathrm{H}$-NMR spectrum and assignment of $\mathrm{PS}_{1-7}$. Peaks marked with asterisks are due to $\mathrm{CHCl}_{3}(7.27 \mathrm{ppm})$ and TMS (0.00 ppm).

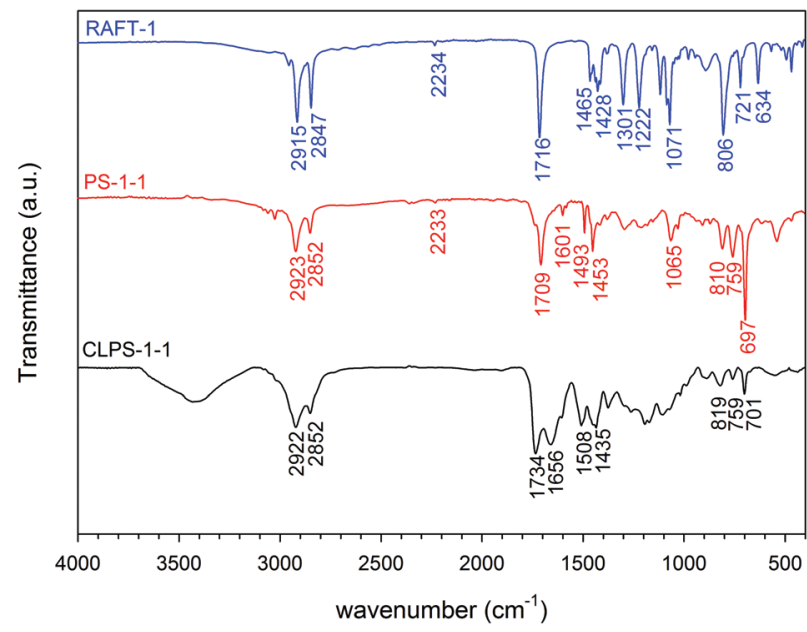

Fig. 3 IR spectrum of CLPS $1-1$, compared to that of PS ${ }_{1-1}$ and RAFT-1.

For most RAFT agents used, the presence of $\mathrm{C} \equiv \mathrm{N}$ stretches at $2233 \mathrm{~cm}^{-1}$ and $\mathrm{C}=\mathrm{O}$ stretches at $1709 \mathrm{~cm}^{-1}$ in IR spectrum (Fig. 3) showed the presence of the expected RAFT agent end group in the final polymers. Stretches for the aromatic $\mathrm{C}=\mathrm{C}$ at 1601,1493 and $1453 \mathrm{~cm}^{-1}$ indicated the incorporation of styrene units as well as monosubstituted phenyl rings at 759 and $697 \mathrm{~cm}^{-1}$. As the molecular weight of linear polystyrene increased, the intensity of $\mathrm{C} \equiv \mathrm{N}$ and $\mathrm{C}=\mathrm{O}$ peaks were suppressed and intensity of aromatic peaks enhanced. GPC data (Table 1) showed that all polymers had narrow molecular weight distributions, with a polydispersity index (PDI) of less than 1.2. The degree of polymerisation (DP) was calculated from the molecular weight $\left(M_{\mathrm{n}}\right)$.

\section{Hypercrosslinking of linear polystyrenes}

The polystyrenes were hypercrosslinked with FDA using a Friedel-Crafts catalysed reaction. ${ }^{19}$ The products were purified by Soxhlet extraction to remove the monomer and catalyst residues providing brown solids in quantitative yields. These are named CLPS $_{x-y}$, for networks formed from the corresponding $\mathbf{P S}_{x-y}$. All networks were insoluble powders, as expected from previous examples. ${ }^{19,50-52}$ Elemental analysis of the networks showed the decrease of $\mathrm{S}$ and $\mathrm{N}$ contents as the degree of polymerisation of the parent polystyrene decreased. The discrepancy between the theoretical and measured data is typical for such HCPs. ${ }^{18,52-54}$ Common explanations include trapped catalyst in the networks, the unreacted end of crosslinkers, or the adsorption of gases and water in the porous structures. ${ }^{55}$

IR spectra (Fig. 3) illustrated the decrease in intensity of the stretching of the monosubstituted phenyl rings (at 760 and $700 \mathrm{~cm}^{-1}$ ) after crosslinking, indicating the success of the reaction. Focusing on the polystyrenes synthesised using RAFT-1, the peak at $1734 \mathrm{~cm}^{-1}$ shows that the carbonyl group survived the polymerisation process.

Davankov and Tsyurupa have suggested that identification of carbonyl groups in hypercrosslinked polymers by IR can be 
difficult because there can be overlapping with bands from the stretching of the phenyl rings at around $1700 \mathrm{~cm}^{-1} .^{55}$ However, the peak at $1734 \mathrm{~cm}^{-1}$ was not present in the crosslinked polystyrene without a carboxylic acid group (for example, for polymers formed from RAFT-4). Nonetheless, this seems a relatively high wavenumber for a carboxylic acid. ${ }^{56}$ Hence, the reaction of RAFT-1 alone with FDA and $\mathrm{FeCl}_{3}$ in DCE was investigated. After reaction, the product showed the shift of carbonyl peak from 176 to 172 ppm as well as the presence of a methoxy peak at $52.1 \mathrm{ppm}$ and in the ${ }^{13} \mathrm{C}$ NMR spectrum and at $3.70 \mathrm{ppm}$ in the ${ }^{1} \mathrm{H}$ NMR spectrum, suggested that the methyl ester is formed during the reaction. ${ }^{57}$ The IR spectrum of the product also showed a band at $1735 \mathrm{~cm}^{-1}$ (see Fig. S1, ESI $\dagger$ ). It seems that the esterification of the carboxylic acid on the RAFT agent can occur. For simplicity, the reaction of decanoic acid with FDA and $\mathrm{FeCl}_{3}$ in DCE was investigated and also clearly showed the methyl ester product. Hence, it appears that the carboxylic acid does not survive the knitting process.

The effect of the DP of the parent polystyrene units on the surface areas of the final networks was studied (Table 2). The porosities were measured by nitrogen sorption at $77 \mathrm{~K}$. Typical nitrogen adsorption isotherms for $\mathbf{C L P S}_{1-\boldsymbol{y}}$ are shown in Fig. 4a. Surface areas were calculated using BrunauerEmmett-Teller (BET) theory. For those polymers formed using RAFT-1, as the DP of the parent polystyrenes increased, the surface areas also increased (Fig. 4b). Crosslinking polystyrenes with DP 5 and 9 provided essentially non-porous networks $\left(\mathrm{SA}_{\mathrm{BET}}<30 \mathrm{~m}^{2} \mathrm{~g}^{-1}\right)$. The surface areas rapidly increased from 222 to $767 \mathrm{~m}^{2} \mathrm{~g}^{-1}$ when crosslinking a polystyrene with a DP of 10 to 21. A further slight increase in $\mathrm{SA}_{\mathrm{BET}}$ was observed with a DP of 32, but there was no significant increase beyond this DP. Further investigation on the hypercrosslinking of commercial polystyrenes with molecular weights of $35 \mathrm{kDa}$,

Table 2 Summary results of crosslinked polystyrenes

\begin{tabular}{|c|c|c|c|c|c|}
\hline \multirow[b]{2}{*}{ Sample } & \multirow[b]{2}{*}{$\% \mathrm{~N}$} & \multirow[b]{2}{*}{$\% \mathrm{~S}$} & \multirow[b]{2}{*}{$\mathrm{SA}_{\mathrm{BET}}\left(\mathrm{m}^{2} \mathrm{~g}^{-1}\right)$} & \multicolumn{2}{|c|}{$\begin{array}{l}\mathrm{CO}_{2} \text { uptakes } \\
\left(\mathrm{mmol} \mathrm{g}^{-1}\right)\end{array}$} \\
\hline & & & & $273 \mathrm{~K}$ & $298 \mathrm{~K}$ \\
\hline CLPS $_{1-1}$ & 2.25 & 4.51 & 9 & 0.73 & 0.45 \\
\hline CLPS $_{1-2}$ & 0.90 & 2.88 & 27 & 1.21 & 0.78 \\
\hline CLPS $_{1-3}$ & 0.83 & 2.48 & 222 & 1.51 & 0.92 \\
\hline CLPS $_{1-4}$ & 0.66 & 2.53 & 366 & 1.29 & 0.81 \\
\hline CLPS $_{1-5}$ & 0.70 & 2.29 & 502 & 1.60 & 0.91 \\
\hline CLPS $_{1-6}$ & 0.53 & 1.27 & 658 & 1.77 & 1.05 \\
\hline CLPS $_{1-7}$ & 0.46 & 1.50 & 767 & 1.87 & 1.13 \\
\hline CLPS $_{1-8}$ & 0.25 & 0.62 & 862 & 2.04 & 1.20 \\
\hline CLPS $_{1-9}$ & 0.21 & 0.57 & 898 & 2.06 & 1.22 \\
\hline CLPS $_{1-10}$ & 0.17 & 0.44 & 974 & 2.17 & 1.30 \\
\hline $\mathrm{CLPS}_{2-1}$ & 1.08 & 3.20 & 59 & 1.44 & 0.90 \\
\hline CLPS $_{2-2}$ & 0.37 & 1.25 & 869 & 2.10 & 1.28 \\
\hline $\mathrm{CLPS}_{3-1}$ & 0.40 & 3.72 & 9 & 1.13 & 0.70 \\
\hline $\mathrm{CLPS}_{3-2}$ & 0.16 & 1.50 & 774 & 1.78 & 1.06 \\
\hline CLPS $_{4-1}$ & 1.48 & 4.41 & 44 & 0.91 & 0.59 \\
\hline $\mathrm{CLPS}_{4-2}$ & 0.53 & 2.17 & 643 & 1.67 & 0.99 \\
\hline CLPS $_{5-1}$ & 1.19 & 3.61 & 8 & 1.65 & 1.02 \\
\hline CLPS $_{5-2}$ & 0.50 & 1.36 & 879 & 2.18 & 1.29 \\
\hline
\end{tabular}

(a)

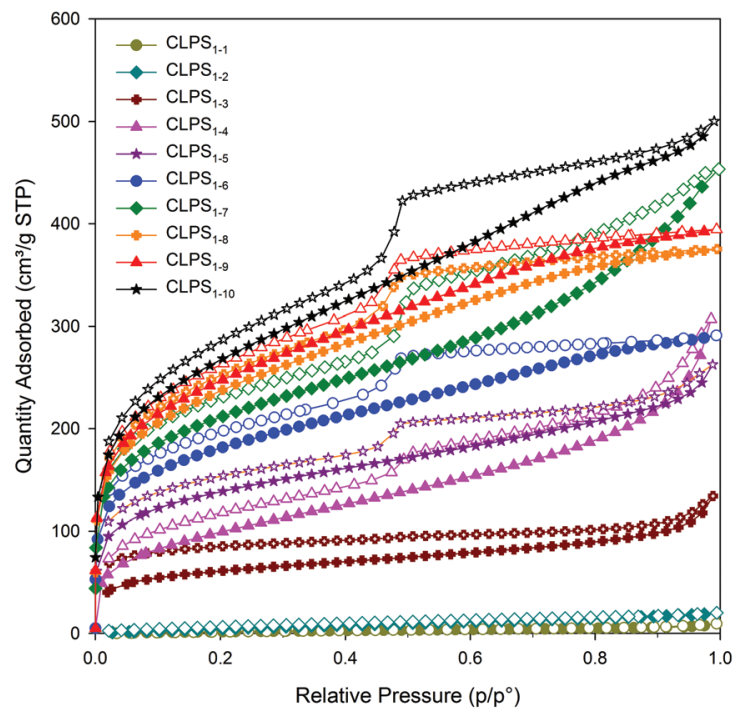

(b)

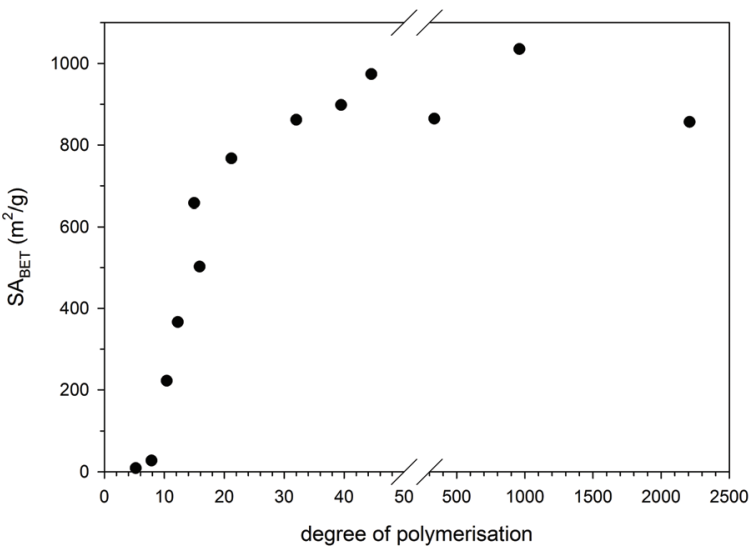

(c)

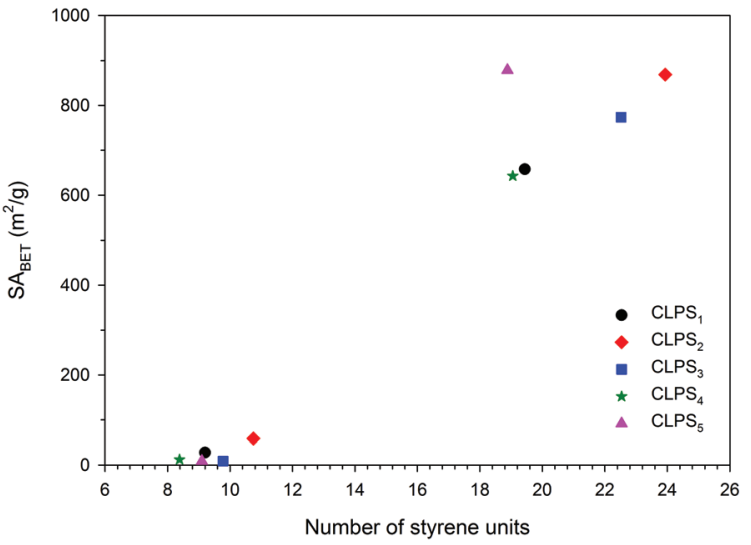

Fig. 4 (a) Nitrogen isotherms of $\mathrm{CLPS}_{1-y}$ collected at $77 \mathrm{~K}$. Adsorption (filled symbols), desorption (hollow symbols). (b) Plot of BET surface areas of CLPS $_{1-y}$ against DP of the parent polystyrene. (c) Plot of BET surface areas of $\mathrm{CLPS}_{x-y}$ synthesised by different RAFT agent.

$100 \mathrm{kDa}$, and $230 \mathrm{kDa}$ (approximate DP of 336, 960 and 2208 respectively), provided networks with surface areas of 865 , 1035 and $856 \mathrm{~m}^{2} \mathrm{~g}^{-1}$, respectively, exhibited no significant change from that of the polystyrenes with DP 21. 
For the networks formed from the other RAFT agents, those with a DP of around 10 were found to be essentially nonporous, whilst those with a higher DP resulted in networks with a $\mathrm{SA}_{\mathrm{BET}}$ of over $600 \mathrm{~m}^{2} \mathrm{~g}^{-1}$ (Fig. 4c). Hence, the surface areas of the networks do not depend on the nature of the RAFT agents used, but mainly on DP of the primary polymer chain.

\section{Conclusions}

We have shown that the surface areas of a series of networks formed by the crosslinking of monodisperse polystyrenes depend on the DP. The nature of the RAFT agent does not seem to affect the porosity of the final networks. At low DP, networks with low porosity are obtained. This is somewhat surprising considering that hypercrosslinking of either benzene or biphenyl leads to networks with high porosity. ${ }^{19}$ There is a gradual increase in porosity as the DP of the parent polystyrene increases up to around a DP of 20. Beyond this, there is little further increase, even when very high DP polymers are used. These data agree with those of Davankov, where the DP was found not to be an important parameter for the high molecular weight polystyrenes used in their study. ${ }^{43}$

The concept of hypercrosslinking polystyrene with a low DP could be used, conceptually, to generate networks with a relatively high percentage of functional groups. However, we show here that carboxylic acids do not survive the crosslinking process. Nonetheless, this functionalization methodology may be more successful if other RAFT agents are used. The need for a DP of greater than approximately 10 to achieve good levels of porosity, however, puts an upper limit on the maximum concentration of functional group that could be incorporated by this method.

\section{Acknowledgements}

TR thanks Mahidol University, Thailand for Funding. DA thanks the EPSRC for a Fellowship (EP/L021978/1). MB thanks the UK EPSRC (Grant EP/H046143) and the UK Regenerative Medicine Platform Safety and Efficacy Hub (MR/K026739/1) for funding. We thank Sean Higgins for running the GPC samples.

\section{Notes and references}

1 R. Dawson, A. I. Cooper and D. J. Adams, Prog. Polym. Sci., 2012, 37, 530-563.

2 C. Xu and N. Hedin, Mater. Today, 2014, 17, 397-403.

3 Z. Chang, D.-S. Zhang, Q. Chen and X.-H. Bu, Phys. Chem. Chem. Phys., 2013, 15, 5430-5442.

4 P. Kaur, J. T. Hupp and S. T. Nguyen, ACS Catal., 2011, 1, 819-835.

5 J. Germain, J. M. J. Fréchet and F. Svec, Small, 2009, 5, 1098-1111.
6 F. Vilela, K. Zhang and M. Antonietti, Energy Environ. Sci., 2012, 5, 7819-7832.

7 X. Feng, X. Ding and D. Jiang, Chem. Soc. Rev., 2012, 41, 6010-6022.

8 S.-Y. Ding and W. Wang, Chem. Soc. Rev., 2013, 42, 548568.

9 P. Kuhn, M. Antonietti and A. Thomas, Angew. Chem., Int. Ed., 2008, 47, 3450-3453.

10 N. B. McKeown, ISRN Mater. Sci., 2012, 2012, 16.

11 S. Xu, Y. Luo and B. Tan, Macromol. Rapid Commun., 2013, 34, 471-484.

12 A. I. Cooper, Adv. Mater., 2009, 21, 1291-1295.

13 C. Pei, T. Ben and S. Qiu, Mater. Horiz., 2015, 2, 11-21.

14 W. Lu, D. Yuan, D. Zhao, C. I. Schilling, O. Plietzsch, T. Muller, S. Bräse, J. Guenther, J. Blümel, R. Krishna, Z. Li and H.-C. Zhou, Chem. Mater., 2010, 22, 5964-5972.

15 D. Yuan, W. Lu, D. Zhao and H.-C. Zhou, Adv. Mater., 2011, 23, 3723-3725.

16 R. Dawson, A. I. Cooper and D. J. Adams, Polym. Int., 2013, 62, 345-352.

17 Y. Zhang and S. N. Riduan, Chem. Soc. Rev., 2012, 41, 20832094.

18 N. Fontanals, J. Cortés, M. Galià, R. Maria Marcé, P. A. G. Cormack, F. Borrull and D. C. Sherrington, J. Polym. Sci., Part A: Polym. Chem., 2005, 43, 1718-1728.

19 B. Li, R. Gong, W. Wang, X. Huang, W. Zhang, H. Li, C. Hu and B. Tan, Macromolecules, 2011, 44, 2410-2414.

20 X. Zhu, S. M. Mahurin, S.-H. An, C.-L. Do-Thanh, C. Tian, Y. Li, L. W. Gill, E. W. Hagaman, Z. Bian, J.-H. Zhou, J. Hu, H. Liu and S. Dai, Chem. Commun., 2014, 50, 7933-7936.

21 M. Saleh, H. M. Lee, K. C. Kemp and K. S. Kim, ACS Appl. Mater. Interfaces, 2014, 6, 7325-7333.

22 Y. Luo, B. Li, W. Wang, K. Wu and B. Tan, Adv. Mater., 2012, 24, 5703-5707.

23 N. O. Calloway, Chem. Rev., 1935, 17, 327-392.

24 K. Jiang, D. Kuang, T. Fei and T. Zhang, Sens. Actuators, B, 2014, 203, 752-758.

25 C. F. Poole, TrAC, Trends Anal. Chem., 2003, 22, 362-373.

26 D. Bratkowska, R. M. Marcé, P. A. G. Cormack, D. C. Sherrington, F. Borrull and N. Fontanals, J. Chromatogr., A, 2010, 1217, 1575-1582.

27 D. Bratkowska, A. Davies, N. Fontanals, P. A. G. Cormack, F. Borrull, D. C. Sherrington and R. M. Marcé, J. Sep. Sci., 2012, 35, 2621-2628.

28 R. Dawson, D. J. Adams and A. I. Cooper, Chem. Sci., 2011, 2, 1173-1177.

29 V. A. Davankov and M. P. Tsyurupa, React. Polym., 1990, 13, 27-42.

30 V. Davankov, M. Tsyurupa, M. Ilyin and L. Pavlova, J. Chromatogr., A, 2002, 965, 65-73.

31 N. Fontanals, R. M. Marcé, P. A. G. Cormack, D. C. Sherrington and F. Borrull, J. Chromatogr., A, 2008, 1191, 118-124.

32 N. Fontanals, P. A. G. Cormack, D. C. Sherrington, R. M. Marcé and F. Borrull, J. Chromatogr., A, 2010, 1217, 2855-2861. 
33 J.-Y. Lee, C. D. Wood, D. Bradshaw, M. J. Rosseinsky and A. I. Cooper, Chem. Commun., 2006, 2670-2672.

34 C. Long, Q. Li, Y. Li, Y. Liu, A. Li and Q. Zhang, Chem. Eng. J., 2010, 160, 723-728.

35 D. C. Sherrington, D. J. Craig, J. Dagleish, G. Domin, J. Taylor and G. V. Meehan, Eur. Polym. J., 1977, 13, 73-76.

36 Z.-A. Qiao, S.-H. Chai, K. Nelson, Z. Bi, J. Chen, S. M. Mahurin, X. Zhu and S. Dai, Nat. Commun., 2014, 5 .

37 H. Binglin, Z. Quanxing, L. Xiaobai, S. Rongfu, S. Zuoqing, G. Xianquan, Z. Xiaolun and W. Jianying, Chin. J. Polym. Sci., 1986, 4, 220-228.

38 M. P. Tsyurupa and V. A. Davankov, React. Funct. Polym., 2002, 53, 193-203.

39 M. P. Tsyurupa and V. A. Davankov, React. Funct. Polym., 2006, 66, 768-779.

40 J.-H. Ahn, J.-E. Jang, C.-G. Oh, S.-K. Ihm, J. Cortez and D. C. Sherrington, Macromolecules, 2006, 39, 627-632.

41 D. C. Sherrington, Chem. Commun., 1998, 2275-2286.

42 B. Li, R. Gong, Y. Luo and B. Tan, Soft Matter, 2011, 7, 10910-10916.

43 V. Davankov and M. Tsyurupa, in Comprehensive Analytical Chemistry, ed. A. D. Vadim and P. T. Maria, Elsevier, 2011, vol. 56, pp. 195-295.

44 D. Zhang, L. Tao, J. Ju, Y. Wang, Q. Wang and T. Wang, Polymer, 2015, 60, 234-240.

45 J. Chiefari, Y. K. Chong, F. Ercole, J. Krstina, J. Jeffery, T. P. T. Le, R. T. A. Mayadunne, G. F. Meijs, C. L. Moad, G. Moad, E. Rizzardo and S. H. Thang, Macromolecules, 1998, 31, 5559-5562.
46 G. Moad, E. Rizzardo and S. H. Thang, Aust. J. Chem., 2009, 62, 1402-1472.

47 J.-P. Gao, W. Wu, L. Rong, G.-L. Mao, Y.-N. Ning, Q.-L. Zhao, J. Huang and Z. Ma, Eur. Polym. J., 2014, 59, 171-179.

48 D. J. Keddie, G. Moad, E. Rizzardo and S. H. Thang, Macromolecules, 2012, 45, 5321-5342.

49 D. J. Keddie, Chem. Soc. Rev., 2014, 43, 496-505.

50 R. T. Woodward, L. A. Stevens, R. Dawson, M. Vijayaraghavan, T. Hasell, I. P. Silverwood, A. V. Ewing, T. Ratvijitvech, J. D. Exley, S. Y. Chong, F. Blanc, D. J. Adams, S. G. Kazarian, C. E. Snape, T. C. Drage and A. I. Cooper, J. Am. Chem. Soc., 2014, 136, 9028-9035.

51 J. Wang, J. Huang, X. Wu, B. Yuan, Y. Sun, Z. Zeng and S. Deng, Chem. Eng. J., 2014, 256, 390-397.

52 M. Errahali, G. Gatti, L. Tei, G. Paul, G. A. Rolla, L. Canti, A. Fraccarollo, M. Cossi, A. Comotti, P. Sozzani and L. Marchese, J. Phys. Chem. C, 2014, 118, 28699-28710.

53 R. Dawson, T. Ratvijitvech, M. Corker, A. Laybourn, Y. Z. Khimyak, A. I. Cooper and D. J. Adams, Poly. Chem., 2012, 3, 2034-2038.

54 G. Liu, Y. Wang, C. Shen, Z. Ju and D. Yuan, J. Mater. Chem. A, 2015, 3, 3051-3058.

55 V. Davankov and M. Tsyurupa, in Comprehensive Analytical Chemistry, ed. A. D. Vadim and P. T. Maria, Elsevier, 2011, vol. 56, pp. 166-193.

56 P. Larkin, in Infrared and Raman Spectroscopy, ed. P. Larkin, Elsevier, Oxford, 2011, pp. 73-115.

57 G. Kida, Y. Yamamoto, Y. Tamura and Y. Higuchi, Japan Pat, JP63066152, 1988. 